\title{
MAGEA10 Positive
}

National Cancer Institute

\section{Source}

National Cancer Institute. MAGEA10 Positive. NCI Thesaurus. Code C131619.

An indication that melanoma-associated antigen 10 expression has been detected in a sample. 